\title{
Research on carbon emission potential of electric vehicles and fuel vehicles
}

\author{
Qiang Zhou ${ }^{1, *}$, Wanfu Liu ${ }^{1}$ and Wuqin $\mathrm{Qi}^{2}$ \\ ${ }^{1}$ School of Mechanical Engineering, Tianjin University of Commerce, Tianjin, China
}

\begin{abstract}
Electric vehicles are considered as a effective tool for energy conservation and emission reduction, Because of its zero direct carbon emissions. However, thermal power generation accounts for a large proportion in China's power generation structure, so the indirect carbon emissions of electric vehicles must be considered. In order to further study the carbon emission potential of electric vehicles compared with traditional fuel vehicles, the direct carbon emission of fuel vehicles and the indirect carbon emission of battery electric vehicles were calculated. The results show that the carbon reduction effect of electric vehicles is obvious, and the coal power technology and the energy structure of power generation have great influence on the carbon reduction potential of electric vehicles. Based on this, suggestions are put forward to promote electric vehicles and fully release their emission reduction potential from the aspects of enhancing consumers' perception of social value, improving energy structure and improving coal power technology.
\end{abstract}

\section{Introduction}

The carbon emission from passenger cars has become one of the main carbon emission sources with the rapid development of the transportation industry. Electric vehicles have become an ideal alternative for transportation because they have no direct carbon emission in the process of use. Considering the high proportion of fossil energy in China's power generation structure, it is not convincing to take no account of the indirect carbon emission of electric vehicles at the power generation. Many scholars have studied the carbon emissions produced by electric vehicles. Menglei Ren et al. built an improved emission index model of electric vehicles and conducted an empirical study on two factors of energy structure and climate. The results show that carbon emissions of electric vehicles have significant spatial variation and are closely related to the proportion of thermal power generation [1]. Wenwei Ke et al. collected the latest data on fuel transportation, pipe end control, actual fuel economy and emissions, and predicted the future energy consumption, carbon dioxide and air pollutant emissions of various light passenger vehicles from well to vehicle (WTW) [2].

As the final customers of electric vehicles, consumers' purchase intention of electric vehicles plays a decisive role in the promotion of electric vehicles. There is a very obvious positive relationship between consumers' purchase intention and perceived value, and perceived value is an important judgment criterion to judge whether a purchase decision is made [3]. According to the research of Sheth et al. on the theory of consumption value in 1991, only when the product contains specific value and satisfies the needs of consumers, consumers are more likely to make purchasing decisions [4]. Based on the consumption value theory, consumers' value perception of electric vehicles can be divided into functional value (use value, price value, convenience value) and non-functional value (emotional value, social value and cognitive value). Every consumer lives in a certain social group, and social factors will inevitably have an impact on consumers' purchasing behaviors. Consumers' perception of the social value of electric vehicles is mainly affected by the carbon emission effect of electric vehicles. Therefore, the carbon emission reduction effect of electric vehicles will have a direct impact on consumers' perception of social value and then their purchase intention.

This paper calculates the carbon emission of traditional fuel vehicles and battery electric vehicles, compares and analyzes the emission reduction potential of these two fuel vehicles, and puts forward suggestions that are helpful to the carbon emission reduction of electric vehicles and further enhance their social value.

\footnotetext{
*Corresponding author: qiangzhouma_eng @163.com
} 


\section{Theoretical analysis of vehicle carbon emission}

At present, there is no consistent and accepted method for calculating vehicle carbon emission globally. The use of full life cycle to comprehensively evaluate the carbon emissions of different vehicles has always been a hot topic in academic research. However, for traditional vehicle fuels, the calculation and quantification of carbon emissions from mining, production and use are difficult due to the diversity, regionalism and timeliness of the process routes and technical routes. Therefore, this paper refers to the calculation method of vehicle carbon emissions in Singapore. For fuel vehicles, For fuel vehicles, only the direct carbon emissions in the vehicle usage stage are calculated without considering the carbon emissions in the traditional fuel mining, production and transportation stages. For pure electric vehicles, indirect carbon emissions during the power generation phase will be calculated [5]. Therefore, the energy flow of fuel vehicles and battery electric vehicles is shown in Figure (1) and (2).

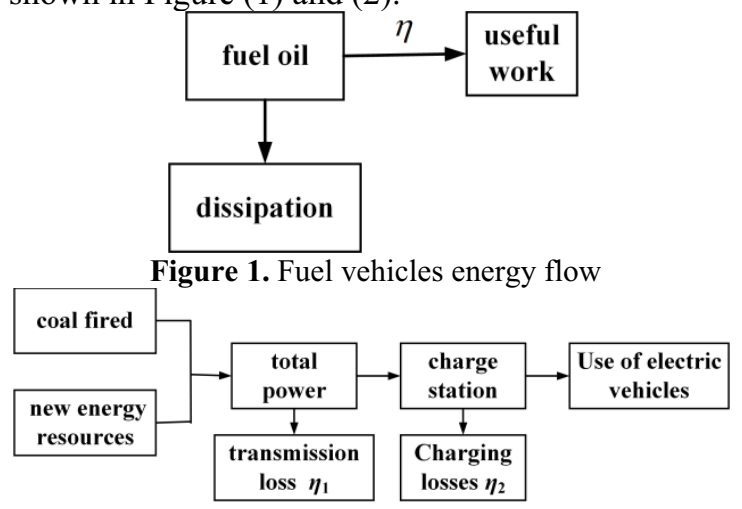

Figure 2. Battery electric vehicles energy flow

It can be seen from Figure (1) and (2) that part of the thermal energy released by the combustion of traditional fuel vehicles is converted into effective work to provide power for the vehicle, while the other part is dissipated in the form of heat. The electric energy that provides power for electric vehicles is first converted into electric energy through different forms of energy such as new energy and coal burning and then transmitted to each charging station through the power grid. Electric vehicles are charged through charging stations. Of course, there is also a certain amount of electric energy loss in the transmission and charging process.

\subsection{Calculation and theoretical analysis of carbon emission from conventional fuel vehicles}

Assuming that all fuels are fully converted to $\mathrm{H}_{2} \mathrm{O}$ and $\mathrm{CO}_{2}$, carbon emissions can be deduced based on the principle of energy conservation. The following is the calculation formula of carbon emission in $100 \mathrm{~km}$ of conventional fuel vehicles.

$$
c_{w}=\frac{100 w k}{q \times \eta}
$$

$c_{w}$ is the vehicle emission of $100 \mathrm{~km}, \mathrm{~kg} / 100 \mathrm{~km} ; q$ is the calorific value of gasoline, $\mathrm{kJ} / \mathrm{L} ; w$ is the effective work per kilometer of the vehicle, $\mathrm{kJ} / \mathrm{km} ; \eta$ is the thermal efficiency of the engine; $k$ is the carbon emission coefficient, $\mathrm{kg} / \mathrm{L}(\mathrm{kg})$. The carbon emission coefficients of various fuels are shown in Table 1.

\begin{tabular}{|c|c|} 
Table 1. Fuel carbon emission factor \\
\hline fuel & carbon emission coefficient \\
\hline gasoline & $2.65(\mathrm{~kg} / \mathrm{L})$ \\
\hline diesel oil & $2.34(\mathrm{~kg} / \mathrm{L})$ \\
\hline standard coal & $2.62(\mathrm{~kg} / \mathrm{kg})$ \\
\hline
\end{tabular}

According to Formula (1), the $100 \mathrm{~km}$ fuel consumption of a car is mainly related to the efficiency of the car engine. The higher the engine efficiency, the lower the $100 \mathrm{~km}$ fuel consumption and the corresponding $100 \mathrm{~km}$ carbon emission will be reduced. Fig. 3 shows the development and changes of the thermal efficiency of gasoline engines [6].

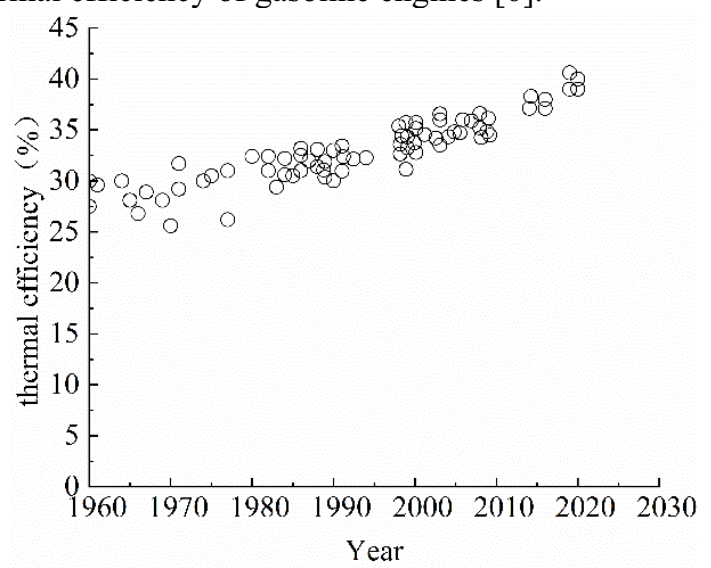

Figure 3. History of engine thermal efficiency

As can be seen from Figure 3, the thermal efficiency of the current engine is about $40 \%$. In the last 60 years, the thermal efficiency of gasoline engines has increased from about $30 \%$ to $40 \%$, and the thermal efficiency has increased by $10 \%$.

\subsection{Carbon emission calculation and theoretical analysis of battery electric vehicles}

When indirect carbon emissions are taken into account, the carbon emissions of electric vehicles are shown in Equation (2).

$$
c_{e}=\frac{q_{e} h c k}{1000\left(1-\eta_{1}\right)\left(1-\eta_{2}\right)}
$$

$c_{e}$ is the indirect $\mathrm{CO}_{2}$ emission of electric vehicle in $100 \mathrm{~km}, \mathrm{~kg} / 100 \mathrm{~km} ; q_{e}$ is the electric energy consumption of an electric vehicle of $100 \mathrm{~km}, \mathrm{kWh} / 100 \mathrm{~km} ; \eta_{1}$ is the loss rate of charging power; $\eta_{2}$ is power transmission loss, $\% ; h$ is the proportion of thermal power generation production, $\% ; c$ is the standard coal consumption per kilowatt-hour of power supply, $\mathrm{g} / \mathrm{kWh}$.

According to the equation (2), The $100 \mathrm{~km}$ carbon emissions of electric vehicles are related to charging loss, transmission loss, thermal power generation ratio and coal consumption per $\mathrm{kWh}$, due to the two factors of 
charge loss and transmission loss change is relatively slow, and power supply standard coal consumption per kilowatt-hour and proportion of thermal power generation influence is relatively large, the power supply standard coal consumption per $\mathrm{kWh}$ in different years and proportion of thermal power shown in figure 4, figure 5 (Source: National Bureau of Statistics).

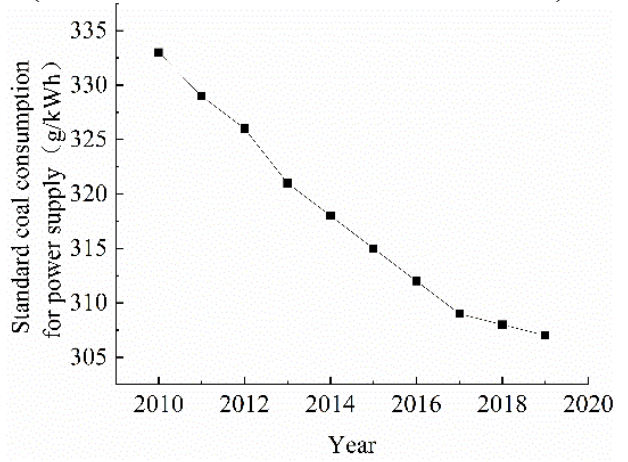

Figure 4. standard coal consumption for power supply

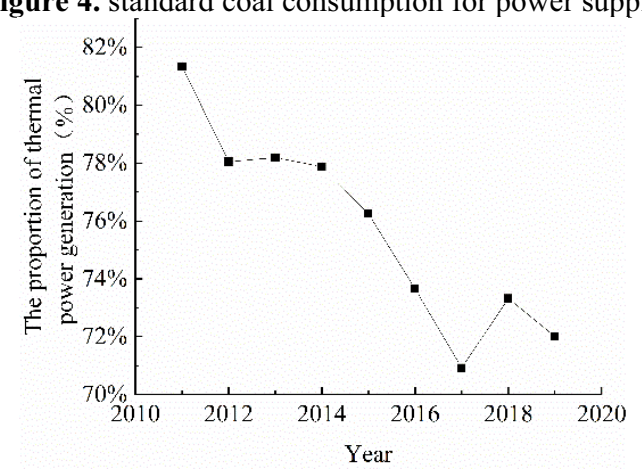

Figure 5. proportion of thermal power generation

As shown in Fig. 4, standard coal consumption of power supply decreases year by year from $333 \mathrm{~g} / \mathrm{kWh}$ in 2010 to $307 \mathrm{~g} / \mathrm{kWh}$ in 2019 . As the standard coal consumption of power supply decreases year by year, the carbon emission of 100 kilometers of electric vehicles will be further reduced. As can be seen from Fig. 5, the proportion of thermal power generation in China is on the decline, from $81 \%$ in 2011 to about $72 \%$ in 2019 .

\section{Carbon emission reduction effect analysis}

According to the national power statistics released by the National Energy Administration, in 2019, the standar coal consumption of power supply for power plants with over $6000 \mathrm{~kW}$ is $307 \mathrm{~g} / \mathrm{kWh}$, the power loss is $5.9 \%$, and the thermal power generation takes up $72 \%$ in 2019 . Charging loss is 7\% [7]. Four hot sales cars in 2020 were selected for carbon reduction analysis, including Qin PRO flagship edition, Qin PRO EV standard, Song PRO Elite and Song PRO EV. According to Equations (1) and (2), carbon emissions of $100 \mathrm{~km}$ of four different vehicle types can be obtained, as shown in Fig. 6 .

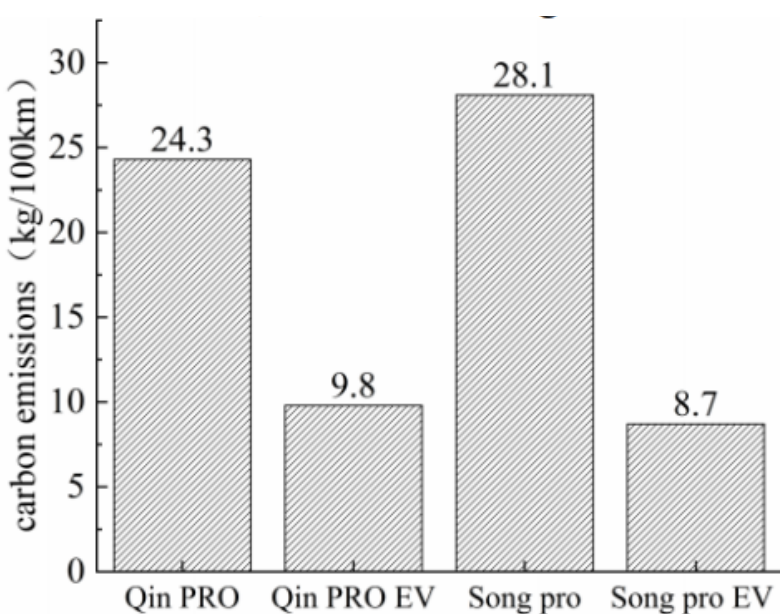

Figure 6. The carbon emission of different models

As Fig. 6 shows, the carbon emission of $100 \mathrm{~km}$ of two battery electric vehicles is $9.8 \mathrm{~kg} / 100 \mathrm{~km}$ and $8.7 \mathrm{~kg} / 100 \mathrm{~km}$ respectively. The $100 \mathrm{~km}$ carbon emissions of the two types of fuel cars are $24.3 \mathrm{~kg} / 100 \mathrm{~km}$ and $28.1 \mathrm{~kg} / 100 \mathrm{~km}$. The $100 \mathrm{~km}$ carbon emissions of electric vehicles account for $35.4 \%$ of the $100 \mathrm{~km}$ carbon emissions of fuel powered vehicles. According to the theoretical analysis of carbon emission, the carbon emission of 100 kilometers of battery electric vehicles is mainly affected by the power energy structure and the coal consumption of power supply standard. It is estimated that by 2030 , the proportion of thermal power generation will drop to about $61 \%$, and the coal consumption of power supply standard will drop to $297 \mathrm{~g} / \mathrm{kWh}$. The thermal efficiency of fuel-powered cars is expected to rise to $42 \%$. It is predicted that by 2030 , carbon emission of $100 \mathrm{~km}$ of battery electric vehicles will drop to $7.6 \mathrm{~kg} / 100 \mathrm{~km}$, and carbon emission of $100 \mathrm{~km}$ of fuel-powered vehicles will drop to $25 \mathrm{~kg} / 100 \mathrm{~km}$. Carbon emission of $100 \mathrm{~km}$ of battery electric vehicles will account for about $30.4 \%$ of that of fuel-powered vehicles.

The use of battery electric vehicles can effectively reduce vehicle carbon emissions, but at present, the sales volume of traditional fuel vehicles still accounts for a large proportion in China's passenger vehicle market. As shown in Fig. 7(Source: China Association of Automobile Manufacturers), although the sales volume of fuel vehicles is declining every year, the total sales volume is much larger than that of battery electric vehicles. And sales of battery electric vehicles ultimately depend on the consumer. From the perspective of improving consumers' perception of social value, the society should strengthen the publicity of the emission reduction effect of electric vehicles, so that consumers have a rational understanding of the specific emission reduction situation of electric vehicles, so that consumers who buy electric vehicles can better obtain social recognition and pride. 


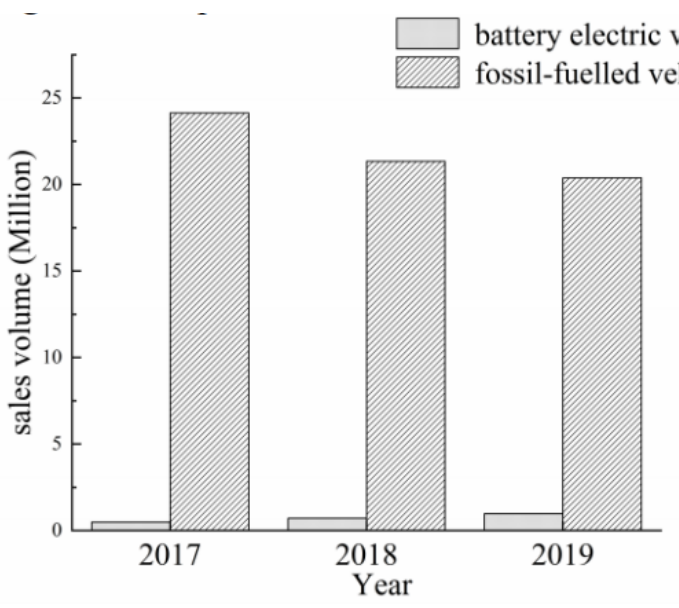

Figure 7. Sales of battery electric and fuel vehicles

The power plant continuously improves the technology to reduce the power supply standard coal consumption, such as IGCC and CCS technology and other energy-saving emission reduction technology; The government vigorously develops all kinds of new energy sources and continuously increases the proportion of new energy in power generation; Car manufacturers are constantly upgrading their technology. There is no doubt that these measures play an important role in energy conservation and emissions reduction. From the point of view of broadening ways to use energy and reduceing energy consumption, we should also give full play to various possibilities of new energy application. For example, direct integration of photovoltaic module electric vehicles can be considered. Some foreign researchers and automobile manufacturers have made some researches and attempts, which can not only save energy and reduce emissions, but also greatly enhance consumers' sense of participation in the process of energy conservation and emission reduction, and greatly promote their perception of social value.

\section{4 conclusion}

1. Carbon emission analysis of battery electric vehicles and fuel vehicles shows that compared with traditional fuel vehicles, battery electric vehicles have great emission reduction potential. Combined with the characteristics that more than $70 \%$ of China's electric power is thermal power generation, coal power technology and energy structure of power generation play a decisive role in the emission reduction potential of battery electric vehicles.

2. At present, the sales volume of fuel vehicles still accounts for a large proportion. It is of great significance to continuously improve consumers' perception of the social value of electric vehicles and let buyers gain a kind of social recognition, which is of great significance to fully release the emission reduction effect of battery electric vehicles.

\section{Reference}

1. Ren, M. L., Yang, B., Li, J., (2019). Greenhouse gas impacts of electric vehicles considering energy mix and climate factors. Journal of Environmental Science, 39(7), 2434-2441.

2. Ke, W. W., Zhang, S. J., He, X. Y., (2017). Well-to-wheels energy consumption and emissions of electric vehicles: Mid-term implications from real-world features and air pollution control progress. Applied Energy, 188, 367-377.

3. Sheth, J. N., Newman, B. I., Gross, B. L., (1991). Why we buy what we buy: A theory of consumption values. Journal of business research, 22, 159-170.

4. Zeithaml, V., (1988). Consumer perceptions of price, quality and value: a means-end model and synthesis of evidence. Journal of Marketing, 52, $2-22$.

5. Wang, H. W., Shi, H., (2018). Analysis of vehicle carbon Emission in Chinese Context. In: Annual report on new energy vehicle industry in china 2018. Chaina Social Sciences Press., Beijing. pp. 403-414.

6. Takahashi, D., Nakata, K., Yoshihara, Y., (2015). Combustion development to achieve engine thermal efficiency of $40 \%$ for hybrid vehicles. SAE Technical Paper2015-01-1254.

7. Wang, J., (2016). Research on high efficiency Electric Vehicle on-board Charger. Master, Yangzhou University, JiangSu China. 